\title{
The Effect of Monosodium L-Glutamate (MSG) Treatment for Short and Long Terms to The Semen Quality of Adult Male Rats
}

\author{
Ivakhul Anzila ${ }^{1}$, Agung Pramana Warih Merhendra² ${ }^{2}$ Sri Rahayu ${ }^{2 *}$ \\ ${ }^{1}$ Master Program of Biology, Faculty of Mathematics and Natural Sciences, University of Brawijaya, Malang, Indonesia \\ ${ }^{2}$ Department of Biology, Faculty of Mathematics and Natural Sciences, University of Brawijaya, Malang, Indonesia
}

\begin{abstract}
This study was conducted to investigate the effect of MSG treatment for short and long term on the semen quality of adult male rats. Twelve male adult Wistar rats with 200-300g of body weight (BW) and 3-4 month of age were used in this study. The animals were divided randomly into 3 groups. M0 was used as a control, M1 and M2 were given with MSG $4 \mathrm{mg} / \mathrm{gBW}$ for 15 and 45 days respectively. The experimental animals were sacrificed on the days $16^{\text {th }}$ (to M1 group) and $46^{\text {th }}$ (to $M 0$ and $M 2$ groups). The epididymis was isolated and semen quality (motility, viability, concentration, and abnormality of sperm) was evaluated. The results showed motility and concentration of M1 and M2 were not significantly decreased compared to MO. MSG treatment also significantly reduced viability and increased abnormality of sperm. Analysis of sperm abnormality character shows that the use of long-term MSG caused a formation of the primary abnormality (round and double head sperm) and increased the secondary abnormality (bent neck, curve tail, coiled tail, headless, and tailless) compared to control. Conclusion, semen quality decreases with consumed MSG for the long term. For this reason, reconsidering the use of MSG as an enhancer for the teste of food is very important.
\end{abstract}

Keywords: epididymis, Monosodium L-Glutamate, semen quality.

\section{INTRODUCTION}

Monosodium L-Glutamate (MSG) is a white crystal-like substance that contains $78 \%$ of glutamic acid, $22 \%$ of sodium and water [1]. The Majority, MSG used as a food additive in everyday life. MSG can increase the taste of umami in food and stimulated of appetite [2]. The production of MSG with the conventional method was made by the molasses fermentation process of Micrococcus glutamicus bacteria [3].

Glutamate given orally into the body will be absorbed by the stomach and small intestine. Then, glutamate entered the bloodstream and dissociated into sodium and L-glutamate [4]. Lglutamate then binds to the NMDA (N-Methyl-DAspartate) receptor in the testes. The bond between L-glutamate and NMDA receptor can open $\mathrm{Ca}^{2+}$ ion channels which cause $\mathrm{Ca}^{2+}$ influx into the intracellular and activate enzymes such as phospholipase and protein kinase. These enzymes lead to the degradation of proteins and membranes [5]. The degradation process of proteins and membranes is accompanied by the release of free radicals in the form of superoxide radical (O2). Superoxide radical (O2) converted to Hydrogen Peroxide $\left(\mathrm{H}_{2} \mathrm{O}_{2}\right)$ by the enzyme

\footnotetext{
* Correspondence address:

Sri Rahayu

Email : yayuksrirahayu8@gmail.com

Address : Dept. Biology, University of Brawijaya, Veteran Malang, Malang 65145.
}

Superoxide Dismutase (SOD). $\mathrm{H}_{2} \mathrm{O}_{2}$ will react with $\mathrm{Fe}^{2+}$ through an Fenton reaction to form Hydroxy Radical $\left(\mathrm{OH}^{-}\right)$and lipid peroxidation [6]. The existence of Hydroxy Radical $\left(\mathrm{OH}^{-}\right)$and lipid peroxidation leads transformation and fragmentation of sperm DNA, necrosis in cells, increasing abnormal of sperm, decreased sperm count [7].

Treatment of MSG at $4 \mathrm{mg} . \mathrm{B} \mathrm{BW}^{-1}$ in rats for 14 and 28 days induced alteration of sperm function in testes include significantly decrease of conversion of spermatogonia to primary spermatocytes and increase the number of inactive spermatogonia compared to controls [8]. Moreover MSG treatment in longterm can cause formation of Reactive Oxygen Species (ROS) [9]. ROS significantly promote in the level of sperm abnormality including abnormal head, normal sperm without the head, normal sperm without the tail (headless), and head without tail (tailless) [10].

In this research, we analyzed the toxic effects of treatment MSG $4 \mathrm{mg} . \mathrm{gBW}^{-1}$ for 15 and 45 days on the semen quality in adult male rats. This study differs from previous studies because it uses two different duration of MSG treatment. The duration treatments are short term for 15 days and long term for 45 days. In addition, sperm abnormality parameters in this study are presented in more detail by counting the number of cells in each type of sperm abnormality. 


\section{MATERIAL AND METHODS}

Twelve male Wistar rats (3-4 months old and 200-350g body weight (BW) were obtained from the Animal Unit Laboratory of Gajahmada University, Yogyakarta, Indonesia. Experimental protocols were accepted by The Research Ethics Committee of Brawijaya University Malang, in accordance to the principles of Animal Care (No: 1067-KEP-UB).

Experimental animals were randomly divided into 3 groups ( $n=4$ per group). Control group (MO): fed standard dies and receiving mineral water; M1 group: given MSG 4mg.gBW-1 for 15 days, and M2 group: given MSG 4mg.gBW-1 for 45 days. MSG was daily administered by oral gavages. The animals were housed in conventional plastic cages measuring $39 \times 30 \times 12$ $\mathrm{cm}$ (4 animals per cage) with wood shavings as bedding and maintained under standard laboratory conditions (in room temperature with a 12h/12-h light/dark cycle). Standard Food (Nova Rabbit Food, Perfect Companion Indonesia Ltd., Indonesia) and water (AQUA Golden Mississippi Indonesia Ltd.) were available ad libitum. Experimental animals were sacrificed using cervical dislocation on days $16^{\text {th }}$ (M1) and $46^{\text {th }}$ ( $M 0$ and $M 2$ ) and the epididymis were removed and stored in buffer.

\section{Semen Collection and Analysis}

Semen were collected from right cauda epididymis. The epididymis was placed and excised in a watch glass contain $1.5 \mathrm{~mL}$ of $\mathrm{NaCl}$ $0.9 \%$ at $37^{\circ} \mathrm{C}$ [11]. The motility, viability, abnormality, and concentration of sperm were examined by a light microscope at 100 and 400x magnifications.

\section{Sperm Motility (SM)}

Total of $10 \mu \mathrm{L}$ semen were added to object glass. The movement of sperm at 5 microscope fields was observed by a light microscope at 100x magnification [12]. The percentage of sperm motility was recorded and scored by McMaster [13].

Table 1. Criteria of Sperm Motility Categorization by McMaster [13]

\begin{tabular}{cl}
\hline Score & Criteria \\
\hline 1 & Very poor (0-20\% progressive motile) \\
2 & Poor $\quad(20-40 \%$ progressive motile) \\
3 & Good $\quad(40-60 \%$ progressive motile) \\
4 & Very good (60-80\% progressive motile) \\
5 & Excellent (80-100\% progressive motile) \\
\hline
\end{tabular}

Sperm Viability (SV) and Abnormality (SA)

Total of $10 \mu \mathrm{L}$ liquid semen was added to object glass and was stained with $1 \%$ eosin $/ 5 \%$ negrosin. Percentage of sperm viability and abnormality was examined by a light microscope at 400x magnification in 3 microscope fields (or up to 200 cells). This is the formulation $[12,14]$ :

$$
\begin{gathered}
\text { SV }(\%)=\frac{\text { livesperm }}{\text { total sperm }} \times 100 \% \\
\text { SA }(\%)=\frac{\text { abnormal sperm }}{\text { total sperm }} \times 100 \%
\end{gathered}
$$

Description:

SV $=$ sperm viability

$\mathrm{SA}=$ sperm abnormality

\section{Sperm Concentration (SC)}

The semen was diluted $50 x(20 \mu \mathrm{L}$ of liquid semen was added to $980 \mu \mathrm{L}$ of fixative solution from (1:1) NaHCO3 and formalin 10\%). The spermatozoa were counted at $400 x$ magnification using a Neubauer Hemocytometer. The number of sperm was calculated at 5 small chambers per sample using formulation (15]:

$$
\mathrm{SC}=\mathrm{n} \times \mathrm{kx} \text { DF } \times 10^{4}
$$

\section{Description:}

$\mathrm{SC}=$ sperm concentration was expressed as $10^{6} \cdot \mathrm{mL}^{-1}$,

$\mathrm{n}=$ number of sperm

$\mathrm{k}=$ number of small chamber calculated

$\mathrm{DF}=$ dilution factor

$10^{4}=$ room volume of hemocytometer

\section{Statistical Analysis}

The data of control and experimental group were presented as mean values and Standart Error (SE). Significant differences among treatment groups was performed using one way ANOVA with SPSS 16.0 for windows program. Result of one way ANOVA analysis is significant difference at $\mathrm{P}<0.05$ and the next analyzed with Least Significant Difference (LSD) test.

\section{RESULT AND DISCUSSION}

The quality of semen was analyzed with the following results:

\begin{tabular}{|c|c|c|c|}
\hline \multirow{2}{*}{$\begin{array}{c}\text { Semen } \\
\text { Quality } \\
\pm \text { SE }\end{array}$} & \multicolumn{3}{|c|}{ Animal Group } \\
\hline & Mo & M1 & M2 \\
\hline \multirow{2}{*}{ SM (\%) } & $70.50 \pm$ & $55.00 \pm$ & $55.00 \pm$ \\
\hline & 6.85 & 4.08 & 10.61 \\
\hline \multirow[b]{2}{*}{ SV (\%) } & $76.57 \pm$ & $52.49 \pm$ & $36.96 \pm$ \\
\hline & 5.38 & $8.59 *$ & $6.75^{* *}$ \\
\hline \multirow{2}{*}{ SA (\%) } & $10.02 \pm$ & 32. $41 \pm$ & $37.94 \pm$ \\
\hline & 1.62 & $2.25^{* *}$ & $2.21^{* *}$ \\
\hline & $100.63 \pm$ & $79.38 \pm$ & $69.38 \pm$ \\
\hline$\left(10^{6} \cdot \mathrm{mL}^{-1}\right)$ & 5.53 & 13.13 & 11.79 \\
\hline \multicolumn{4}{|c|}{$\begin{array}{l}\text { Notes: } \mathrm{SM}=\text { Sperm Motility, SV = Sperm Viability, } \mathrm{SA}= \\
\text { Sperm Abnormality, SC = Sperm Concentration, } \mathrm{SE}= \\
\text { Standard Error, } \mathrm{M0}=\text { Control, } \mathrm{M} 1=\text { treatment MSG for } \\
15 \text { days, } \mathrm{M} 2=\text { treatment MSG for } 45 \text { days, } \\
{ }^{*}(\mathrm{p} \leq 0,05),{ }^{* *}(\mathrm{p} \leq 0,01)\end{array}$} \\
\hline
\end{tabular}

Table 2. The effects of MSG treatment on semen quality of the adult male rats 


\section{Sperm Motility}

Treatment of MSG 4mg.gBW ${ }^{-1}$ once daily for 15 days (M1) and 45 days (M2) no significanly reduced motility of sperm from 70.50 to $55 \%$ as compered to control group (Table 2). Although, there were no significant differences in the sperm motility between $\mathrm{M} 1$ and $\mathrm{M} 2$ but the use of MSG short and long-term induced a decrease in the percentage of sperm motility by $15.5 \%$ under the control value.

The result showed that treatment with MSG caused a decrease in sperm motility compared to control. In rats, the sperm motility value was acceptable as normal motility over 70\% [16]. Reduction of sperm motility can be affected by disrupted of the spermatogenesis in testes and sperm maturation in epididymis $[17,18]$. The inhibition of the process of spermatogenesis was caused by a greater extent of oxidative damage in the testis. The long term (for 30 days) of MSG exposure to male rats enhance significantly of the lipid peroxidation level of the testes. The lipid peroxidation is the generation of Reactive Oxygen Species (ROS) [9]. High level of ROS in spermatozoa significantly decreased mitochondrial function and caused Adenosine Triphosphat (ATP) depletion [18]. The ATP was requeired by the sperm to mobility and capacitation process [20]. Moreover, ROS can cause the disruption of membrane fluidity. So, the ATP depletion and disruption of membrane fluidity can lead to loss of sperm motility [21]. ROS can reduce sperm motility and the ability of sperm capacitation through the pathways of membrane fluidity alteration, leading to an alterationin sperm motility parameters (22].

\section{Sperm Viability}

The sperm viability on male rats of $\mathrm{MO}$ group was reduced significantly after MSG treatment (M1 and M2 groups). The highest of sperm viability was found in $\mathrm{M} 0$ group and the lowest in the $\mathrm{M} 2$ group with a reduction by $39.61 \%$ (Table 1). The treatment of MSG at longer term for 45 days caused a very significantly reduced of the sperm viability from adult male rats.

The consumption of MSG-induced the destroyer of a lipid membrane by elevated ROS [23]. The lipid membrane was composed of abundant Polyunsaturated fatty acids (PUFAs) which are the targets of ROS. ROS steal electrons from PUFAs of a cell membrane and initiating lipid peroxidation. Peroxidation of PUFAs in sperm cell membranes can give to cell dysfunction with loss of membrane function and integrity [24]. Degenerative of sperm membranes can cause reducing of membrane fluidity which makes a sperm die quickly and decrease of sperm viability [18].

\section{Sperm Abnormality}

The orally given of MSG for 15 and 45 days both induced a significant elevated of the sperm abnormality over the control group values (22.39 and $27.92 \%$, respectively) (Table 1 ). The percentage of sperm abnormality (both primary and secondary abnormal) was very significantly increased $(p \leq 0.01)$ in the MSG treatment group (M1 and M2) compared to the control group (Figure 1). Primary abnormal only occurred in the $\mathrm{M} 2$ group at $0.47 \%$. The highest enhancement of secondary abnormal occurred in the $\mathrm{M} 2$ group (27.44\%), followed by the M1 group (22.39\%).

Sperm abnormality was divided into primary and secondary abnormality [25]. Primary abnormality is abnormality occurring during the spermatogenesis process in testes such as double head, double tail, round head, rudimentary tail and droplet cytoplasm [26]. Secondary abnormality arises during epididymal maturation, transit or ejaculation of sperm such as the bent neck, bent tail, curved tail, headless (normal sperm without head), tailless (normal sperm without tail), and coiled tail [10].

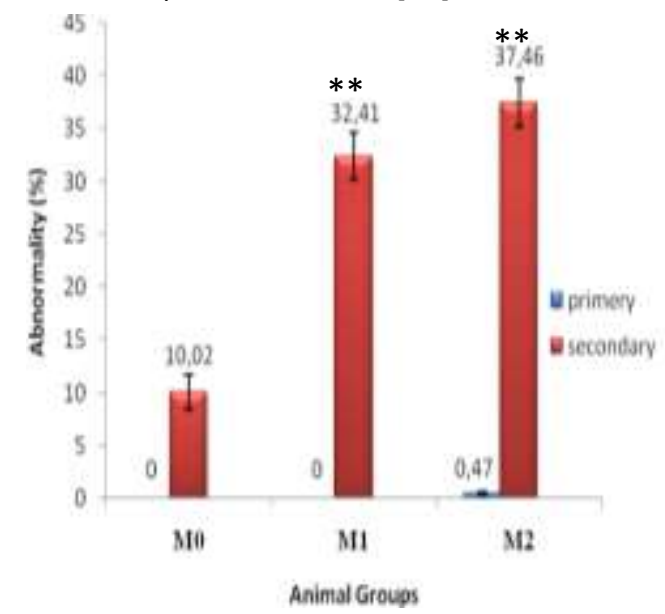

Figure 1. Effect of MSG treatment in the type of sperm abnormality. M0 (Control), M1 (treatment MSG for 15 days), M2 (treatment MSG for 45 days)

The primary abnormal was only found in the M2 group with double and round head characters (Table 3). The secondary abnormal types found in all type abnormal include the headless, bent neck, curved tail, coiled tail and tailless, while coiled tail in M2 group only. The bent neck character about 121 cells (M1 group) and 161 cells (M2 group) was the most significant 
increase as compared control. It is showed that

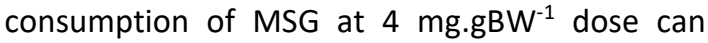
cause an increase of secondary abnormality and on long-term administrated of MSG lead to the formation of primary abnormality such as the double and round head characters.

Table 3. Character of sperm abnormality in male rats which treated $4 \mathrm{mg} . \mathrm{gBW}^{-1} \mathrm{MSG}$.

\begin{tabular}{|c|c|c|c|c|c|}
\hline AT & AP & Character & Mo & M1 & M2 \\
\hline Primary & Head & $\begin{array}{l}\text { Double } \\
\text { Head } \\
\text { Round } \\
\text { Head }\end{array}$ & & & 1 \\
\hline \multirow{5}{*}{ Secondary } & Head & Headless & 52 & 70 & 71 \\
\hline & $\begin{array}{l}\text { Mid } \\
\text { piece }\end{array}$ & Bent neck & 32 & 153 & 193 \\
\hline & \multirow{3}{*}{ Tail } & Coiled-tail & & & 10 \\
\hline & & Curved tail & 12 & 64 & 56 \\
\hline & & Tailless & 24 & 86 & 72 \\
\hline \multicolumn{3}{|c|}{ Total number of normal sperm } & 1097 & 797 & 669 \\
\hline \multicolumn{3}{|c|}{ Total number of abnormal sperm } & 120 & 373 & 407 \\
\hline
\end{tabular}

Notes: $\mathrm{AT}=$ Abnormal Type, $\mathrm{AP}=$ Abnormal Position, $\mathrm{M0}=$ Control, $\mathrm{M} 1=$ treatment $\mathrm{MSG}$ for 15 days, M2 = treatment MSG for 45 days.

The characteristics of sperm abnormality that occur in this research include double head, round head, bent neck, curved tail, coiled-tail, headless, and tailless. Abnormal sperm has different forms compared to normal sperm (Fig. 2). The normal sperm has a curved pointed head shape like a hook with a long straight tail (Fig. 2a). Double head sperm has 2 heads attached to one tail (Fig. $2 \mathrm{~b})$. The round head sperm type has a rounded head shape, not like a hook (Fig. 2c). Bent neck sperm has bent form in midpiece of sperm so the head point to approach the tail (Fig. 2d). Curved tail sperm has unstraight of the tail (Fig. 1e), the contrast to coiled-tail form has a circular tail (Fig. $2 f)$. The headless character is normal sperm without a head (Fig. 2g), while the tailless is normal sperm without a tail (Fig. 2h).

High level of glutamate in the body can increased intracellular calcium level and cause the excessive influx of calcium ions into the mitochondria. It consequently increases the production of ROS [27]. ROS have the ability to directly attack of the purine and pyrimidine bases and degradation of sperm DNA (DNA damage). The DNA damage occured via cross-links, single and double-strand DNA breaks, and chromosomal rearrangements [28]. DNA damage during specific stages of spermatogenesis can cause inhibition of sperm maturation [18]. DNA fragmentation can inhibit the process of spermiation. It will induce the formation of primary abnormality sperm [29]. While secondary abnormality also occurs because of hyperviscosity semen in the epididymis. Hyperviscosity caused by the functional changes of the accessory gland due to a decrease in SOD [30]. So, MSG was increase abnormal of the sperm [31].

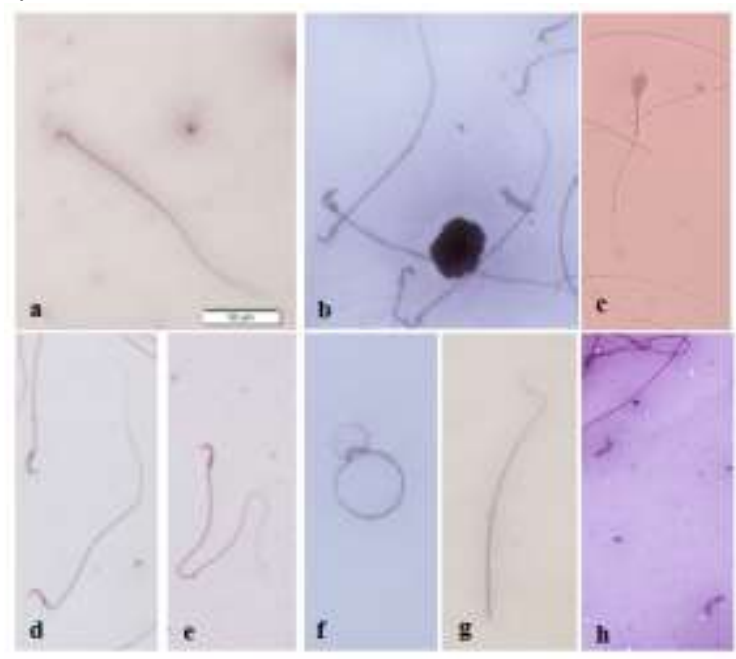

Figure 2. Effect administration of MSG in the character of sperm abormality in adult male rats. Normal sperm (a), Double head (b), Round head (c), Bent neck (d), Curved tail (e), Coiled tail (f), Headless $(\mathrm{g})$, and tailless $(\mathrm{h})$.

\section{Sperm Concentration}

The sperm concentration between the control and experimental group showed no significant differences $(p>0.05)$. The treatment groups (M1 and $\mathrm{M} 2$ ) with orally administered of $4 \mathrm{mg} \mathrm{gBW}^{-1}$ MSG showed a reduction of sperm concentration by $21.25 \%$ and $31.25 \%$ respectively compared the control group. The use of MSG for the long term reduce sperm concentration.

The treatment of MSG could increases of Malondialdehyde (MDA) level in testes, epididymis, and accessory gland via [27,32]. MDA is the result of lipid peroxidation process which used as indicated of ROS formation [28]. The formation of ROS initiated the impairment of mitochondrial membrane fluidity, promote a membrane fusion and then decrease of ionic channels and inactivation of membrane enzymes activity [30]. Moreover, ROS can lead to DNA mutation or fragmentation, and protein oxidation. It will cause DNA damage, cell cycle irregularity, DNA repair or replication disorder and gene mutations of cells. The abnormal cell initiated the apoptotic and necrotic process [31]. The process of apoptotic and necrotic on damaged and inactive cells causes reduced sperm production in semen [32]. 


\section{CONCLUSION}

The results indicate that adult male rats treatment with the dose $4 \mathrm{mg} . \mathrm{gBW}^{-1}$ of MSG had deterioration of semen quality. The deterioration of semen quality involves reduced sperm motility, sperm viability, and sperm concentration. Moreover, MSG consumed in the long term was significantly increased sperm abnormality especially on the number of primary abnormal. Therefore, reconsidering the use of MSG as an enhancer for the teste of food is very important.

\section{ACKNOWLEDGEMENT}

The authors would like to thanks to The Indonesian Government for The Directorate of Research and Society Dedication; The Directorate General of Affirmation Research and Development; and The Ministry of Research, Technology and High Education have funded this research according to the research contract number: 055/SP2H/LT/DRPM/2019, March 11 2019.

\section{REFERENCES}

[1] Alalwani, A.D. 2014. Monosodium glutamate induced testicular lesions in rats (histological study). Middle East Fertil. Soc. J. 19. 274-280.

[2] Henry, H.N. 2017. Review update on food safety of Monosodium L-Glutamat (MSG). Pathophysiology. 24. 243-249.

[3] Jinap, S., P. Hajeb. 2010. Research review Glutamat: its application in food and contribution to health. Appetite. 55. 1-10.

[4] Hinoi, E., T. Takarada, T. Ueshima, Y. Tsuchihashi, Y. Yoneda. 2004. Glutamate signaling in peripheral tissues. Eur. J. Biochem. 271. 1-13.

[5] Kazmi, Z., I. Fatima, S. Perveen, S.S. Malik. 2017. Monosodium Glutamate: Review on clinical reports. Int. J. Food Prop. 20(S2). S1807-S1815.

[6] Agarwal, A., G. Virk, C. Ong, S.S.D Plessis. 2014. Effect of Oxidative Stress on Male Reproduction. World J. Mens Health. 32(1). 1-7.

[7] Turner, T.T., J.J. Lysiak. 2008. Review oxidative stress: A common factor in testicular dysfunction. J. Androl. 29(5). 488498.

[8] Kianifard, D. 2015. Protective effects of Morus Alba (M. Alba) extract on the alteration of testicular tissue and spermatogenesis in adult rats treated with
Monosodium Glutamate. Med. Sci. 4(1). 1947-1958.

[9] Vinodini, N.A., A.K. Nayantara, G.K.M. Damora, B. Ahamed, C. Ramaswamy, Shabarinath, M.R. Bhat. 2008. Effect of mono sodium glutamate- induced oxidative damage on rat testis. J. Chinese Clin. Med. 3(7). 370-373.

[10] Adb, R.N. 2017. Effect of MSG as of food additive on organo-somatic indicator dan sperm abnormalities in adult male mice. Sci. J. Med. Res. 1(2). 46-50.

[11] Aral, F., F. Karacal, F. Baba. 2008. The effect of enroflaxacin on sperm quality in male mice. Res. Vet. Sci. 84. 95-99.

[12] Brazil. C. 2010. Practical semen analysis: from A to Z. Asian J. Androl. 12. 14-20.

[13] Rikianto, D.A., A. Soeprijanto, Y. Kilawati. 2017. The effect of electroporation method towards the motility and viability of Java Barb Fish (Puntius javanicus) sperm. J. Exp. Life Sci. 7(1). 11-16.

[14] Sikka, S.C., A. Ahmet. 2018. Standardized semen analysis and quality control management for multicenter male reproductive toxicology clinical trials. Bioenvironmental Issues Affecting Men's Reproductive and Sexual Health. 23(2). 371386.

[15] Franken, D.R., S. Oehninger. 2012. Semen analysis and sperm function testing. Asian $\mathrm{J}$. Androl. 14. 6-13.

[16] Creasy, D.M., R.E. Chapin. 2013. Haschek and Rousseaux's Handbook of toxicologic pathology, $3^{\text {rd }}$ Ed. Reproductive and Developmental Toxicology. Available at: https://www.sciencedirect.com/topics/medi cine-and-dentistry/sperm-motility

[17] Adamkovicavo, M., R. Toman, M. Martinikova, R. Omelka, R. Babosova, V. Krajcovicova, B. Grosskopf, P. Massanyi. 2016. Sperm motility and morphology changes in rats exposed to cadmium and diazinon. Reprod. Biol. Endocrinol. 14(42). 27.

[18] Wagner, H., J.W. Cheng, E.Y. Ko. 2018. Role of reactive oxygen species in male infertility: An updated review of literatute. Arab J Urol. 16. 35-43.

[19] Basal, A.K., G.S. Bilasputri. 2011. Impact of Oxidative Strees and Antioxidants on Semen functions. Vet. Med. Int. 1-7.

[20] Turner, R.M. 2006. Moving to beat: a review of mammalian sperm motility regulation. Fertil. Dev. 18. 25-38. 
[21] Agarwal, A., G. Virk, C. Ong, S.S.D. Plessis. 2014. Effect of oxidative stress on male reproduction. World J. Mens Health. 32(1). 1-7.

[22] El-Sawy, H.B., M.M. Soliman, S.A. El Shazly, H.A.M. Ali. 2018. Protective effects of camel milk and vitamin $E$ against monosodium glutamate induced biochemical and testicular dysfunctions. Prog. Nutr. 20(1). 76-85.

[23] Kadir, R.E., G.O. Omotoso, T.J. Balogun, A.O. Oyewopo. 2011. Effects of Monosodium Glutamate on semen quality and the cytoarchitecture of the testis of adults Wistar Rats. Int. J. Biomed. Health Sci. 7(1). 39-46.

[24] Ogbuewu, I.P, N.O. Aladi, I.F. Etuk, M.N. Opara, M.C. Uchegbu, I.C. Okoli and M.U. Iloeje. 2010. Relevance of Oxygen Free Radicals and Antioxidants in Sperm Production and Function. Res. J. Vet. Sci. 3. 138-164.

[25] Saba, A.B., O.A. Oridupa, M.O. Oyeyemi, O.D. Osanyigbe. 2009. Spermatozoa morphology and characteristics of male wistar rats administered with ethanolic extract of Lagenaria Breviflora Roberts. Afr. J. Biotech. 8(7). 1170-1175.

[26] Olugbenga, O.M., S.G. Olukole, A.T. Adeoye, A.D. Aadejoke. 2011. Semen characteristics and sperm morphological studies of the West African Dwarf Buck treated with Aloe vera gel extract. Irian J. Reprod. Med. 9(2). 83-88.

[27] Hanipah, E. N. A., N.J. Yahya, E.M. Ajik, N. A. Yusoff, I. S. Taib. 2018. Monosodium glutamate induced oxidative stress in accessory reproductive organs of male Sprague-Dawley Rats. Jurnal Sains Kesihatan Malaysia Isu Khas. 67-73.

[28] Kothari, S., A. Thompson, A. Agarwal, S.S. Du Plessis. 2010. Free radicals: their beneficial and detrimental effects on sperm function. Indian J. Exp. Biol. 48. 425-235.

[29] Marzony, E.T., M. Ghanei, Y. Panahi. 2016. Relationship of oxidative stress with male infertility in sulfur mustard-exposed injuries. Asian Pac. J. Reprod. 5(1). 1-9.

[30] Patricio, A., D.F. Cruz, J.V. Silva, A. Padrao, B.R. Correia, L.K. Gregorio, R. Ferreira, N. Maia, S. Almeida, J. Lourenco, V. Silva, M. Fardilha. 2016. Relation between seminal quality and oxidative balance in sperm cells. ACTA Urologica Portuguesa. 33(1). 6-15.
[31] Sakr, S.A., G.M. Badawy. 2013. Protective effect of Curcumin on Monosodium Glutamate - induced reproduction Toxicity in male Albino rats. Global J. Pharmacol. 7(4). 416-422.

[32] Hamza, R.Z., M.S. Al-Harbi. 2014. Monosodium glutamate induced testicular toxicity and the possible ameliorative role of vitamin E or selenium in male rats. Toxicol. Rep. 1. 1037-1045.

[33] Ataseven, N., D. Yuzbasioglu, A.C. Keskin, F. Unal. 2016. Genotoxity of monosodium glutamate. Food Chem. Toxicol. 91. 8-18.

[34] Agarwal, A., K. Makker, R. Sharma. 2008. Clinical relevance of oxidative stress in male factor infertility: an update. Am. J. Reprod. Immunol. 59. 2-11. 